\title{
ESPAÇOS LIVRES, PADRÕES MORFOLÓGICOS E APROPRIAÇÕES PÚBLICAS NA METRÓPOLE PAULISTANA
}

\author{
OPEN SPACES, MORPHOLOGICAL PATTERNS AND PUBLIC APPROPRIATIONS \\ IN METROPOLIS OF SÃO PAULO
}

\author{
Eugenio Fernandes Queiroga ${ }^{1}$
}

Universidade de São Paulo, São Paulo, SP, Brasil, queiroga@usp.br

\section{Resumo}

A morfologia da metrópole paulistana é o resultado de relações complexas entre processos sociais e o suporte biofísico, apresentando qualidades e desafios inerentes a seu porte (uma das quatro maiores metrópoles do planeta) e a sua inserção na formação socioespacial brasileira. Neste contexto objetiva-se compreender aspectos de sua estrutura morfológica e de seu sistema de espaços livres. A partir de análise visual de imagens de satélite, bem como do uso do aplicativo Google Street View, o Laboratório Quadro do Paisagismo da Faculdade de Arquitetura e Urbanismo da Universidade de São Paulo - Lab QUAPÁ - produziu minuciosa cartografia temática em SIG sobre padrões morfológicos e espaços livres, quadra a quadra, para toda a área conurbada da Região Metropolitana de São Paulo. A análise dessa cartografia temática é apoiada também em dados censitários cartografizados e em amplo acervo de fotos realizadas a partir de sobrevoos sobre a metrópole. Esse artigo traz uma síntese dos principais resultados obtidos, com ênfase no sistema de espaços livres, abordando também reflexões relativas à apropriação pública deste sistema, decorrentes da experiência de orientação de diversos trabalhos científicos de graduação e pós-graduação. Tem-se um quadro que mostra uma metrópole fortemente conurbada, densamente construída, mas ainda apresentando notável predominância de morfologias horizontais. O sistema de espaços livres da metrópole paulistana contém significativos remanescentes de Mata Atlântica, mas apresenta-se, via de regra, pouco competente para o atendimento das diversas demandas sociais e ambientais.

Palavras-chave: Metrópole paulistana. Sistema de espaços livres. Padrões morfológicos. Apropriações.

\begin{abstract}
The morphology of metropolis of São Paulo is the result of complex relations between social process and biophysical support, presenting qualities and challenges inherent to its size (one of the four largest metropolises on the planet) and its insertion in the Brazilian socio-space process. In this context, the objective is to understand aspects of its morphological structure and its open spaces system. From visual analysis of satellite images and the use of Google Street View software, the Laboratorio Quadro do Paisagismo da Faculdade de Arquitetura e Urbanismo da Universidade de São Paulo - Lab QUAPÁ - produced detailed thematic cartography in GIS about morphological patterns and open spaces, block by block, for all juxtaposed urbanization of São Paulo Metropolis. The analysis of this thematic mapping is also supported by mapped census data and in a big collection of photos taken from overflights of the metropolis. This article provides a summary of the main results, with emphasis on open spaces system also addressing reflections on appropriations public of this system, resulting from the orientation experience of many scientific works undergraduate and graduate. This is a synthesis that shows a strong process if conurbation of the metropolis, but still showing a remarkable predominance of morphologies. The open spaces system of the metropolis contains significant remnants of Atlantic Forest, but is, as a rule, little competent to meet the various social and environmental demands.ds.
\end{abstract}

Keywords: Metropolis of São Paulo. Open spaces system. Morphological patterns. Appropriations.

How to cite this article:

QUEIROGA, Eugenio Fernandes. Espaços livres, padrões morfológicos e apropriações públicas na metrópole paulistana. PARC Pesquisa em Arquitetura e Construção, Campinas, SP, v. 7, n. 3, p. 178-188, out. 2016. ISSN 1980-6809. Disponível em: <http://periodicos.sbu.unicamp.br/ojs/index.php/parc/article/view/8647244>. Acesso em: 15 mar. 2017. doi:http://dx.doi.org/10.20396/parc.v7i3.8647244. 


\section{Introdução}

A Região Metropolitana de São Paulo (RMSP), composta por 39 municípios, foi instituída oficialmente por lei federal em 1973. Em 2016 sua população supera 21 milhões de habitantes (10\% da população do país) enquanto seu Produto Interno Bruto (PIB) corresponde a cerca de $18 \%$ do PIB brasileiro (EMPLASA, 2016). A RMSP possuía, em 2014, cerca de 12 milhões de veículos, ou pouco mais de um quarto da frota nacional (DENATRAN, 2016). Tudo isso numa área de quase 8 mil $\mathrm{km}^{2}$, ou seja, somente $0,093 \%$ do território nacional!

A capital paulista, com mais de 12 milhões de habitantes representa mais da metade da população da RMSP, seu PIB é da ordem de $60 \%$ do PIB da RMSP. O município de São Paulo vem gradativamente perdendo relevância na produção industrial em relação à RMSP, ao estado de São Paulo e ao Brasil, por outro lado concentra cada vez mais a oferta de serviços especializados e se constitui na capital financeira do país. São Paulo, com cerca de 5,5\% da população do Brasil, possui 10,5\% dos automóveis da frota nacional (DENATRAN, 2016). A cidade é forte concentradora da riqueza nacional, mas, dialeticamente, apresenta enormes desigualdades, que se expressam, entre outros, na presença de $12,3 \%$ das habitações subnormais do país (IBGE, 2016). Se em 2010 o IDH brasileiro era 0,715 , o IDH paulistano era 0,805 , mas alguns de seus distritos mais ricos possuíam IDH superior a 9,5, superior, inclusive, ao IDH da Dinamarca, enquanto outros, mais periféricos, não atingiam a 7,5.

O contraste se verifica também entre os demais municípios da RMSP. Enquanto as principais cidades da Região do ABC (Santo André, São Bernardo e São Caetano do Sul) possuem IDH muito alto (acima de 0,8), municípios mais periféricos, como Francisco Morato e Cajamar não chegam a 7,3. As escalas demográficas também revelam aspectos da heterogeneidade da RMSP. Guarulhos é a maior cidade brasileira entre as que não são capitais, com mais de 1,3 milhões de habitantes; há ainda mais três municípios na RMSP com população superior a 690 mil habitantes, por outro lado oito cidades da metrópole não chegam sequer a 50 mil habitantes (IBGE, 2016).

A RMSP extravasa sua dinâmica para um território mais vasto, interagindo fortemente com outras aglomerações urbanas, constituindo-se no principal núcleo do Complexo Metropolitano Expandido (do estado de São Paulo), que inclui oficialmente as regiões metropolitanas (RMs) da Baixada Santista, de Campinas, de Sorocaba e do Vale do Paraíba e Litoral Norte e ainda os aglomerados urbanos (AUs) de Jundiaí e de Piracicaba. Extraoficialmente, a RMSP participa de verdadeira estrutura megalopolitana que inclui, além das RMs citadas, as RMs de Ribeirão Preto e do Rio de Janeiro, avançando ainda para o Sul de
Minas e para outras regiões dos estados de São Paulo e do Rio de Janeiro (QUEIROGA, 2002).

Para efeito deste artigo, uma delimitação operacional se faz necessária, assim, adotamos como recorte analítico a mancha urbana contínua que envolve vinte municípios da RMSP, dando destaque para a capital de São Paulo, não apenas por sua indiscutível relevância econômica, demográfica e política, bem como por ser centro difusor em escala nacional de cultura urbanística, de formas de gestão, planejamento e produção capitalista do espaço urbano.

Situada quase inteiramente na bacia do Alto Tietê, a Região Metropolitana de São Paulo se espraia "desrespeitosamente" ao longo de várzeas e colinas, morros e morrotes. Sobretudo ao longo do sentido LesteOeste, já que a Norte e a Sul encontram-se barreiras físicas mais expressivas, as Serras da Cantareira e do Mar, respectivamente, que impõem descontinuidades no processo de urbanização e conurbação com os municípios da RMSP a norte e com a RM da Baixada Santista a Sul. Ocupando várzeas e sítios pré-câmbricos de maneira descontrolada, a metrópole assiste sistematicamente a desmoronamentos e enchentes com graves consequências sociais e econômicas.

A maior parte de seus principais cursos d'água (Tietê, Pinheiros, Tamanduateí, Aricanduva etc.) sofreu severo impacto da urbanização, sendo, via de regra, margeados por avenidas de fundo de vale e apresentam-se fortemente poluídos, neles ainda se despeja grande parte dos esgotos sanitários sem nenhum tratamento (Figura 1). Nas áreas de urbanização mais consolidada grande parte da impressionante rede de pequenos cursos d'água da metrópole foi tamponada e se presta como condutora de esgoto.

A área urbana da RMSP é extremamente impermeabilizada; com arborização mais significativa concentrada em poucas áreas (vide Figura 7). Neste contexto físico-ambiental e de mobilidade fortemente dependente de veículos automotivos, o sistema de espaços livres existente está longe de ser adequado ao controle ambiental bem como ao cotidiano da população, na medida em que a grande parte de seus elementos ou está mal dimensionada, ou ainda é insuficiente em número e distribuição para atender as demandas atuais e potenciais.

Discorre-se neste artigo sobre aspectos ainda muito pouco trabalhados na escala da metrópole paulistana pelas áreas do paisagismo, do planejamento urbano e do urbanismo: o sistema de espaços livres e os padrões morfológicos. São temas imbrincados, extremamente relevantes para a qualidade da vida urbana cotidiana, bem como para a esfera pública. Lamentavelmente, tais questões não têm sido priorizadas pelo planejamento urbano no estado de 
São Paulo, entre outras razões, também pela baixa atenção dada, via de regra, à interação entre paisagismo e morfologia urbana nas faculdades de arquitetura e urbanismo paulistas.

Figura 1 - Foz do Rio Pinheiros no Rio Tietê, entrecortados por complexo de vias expressas

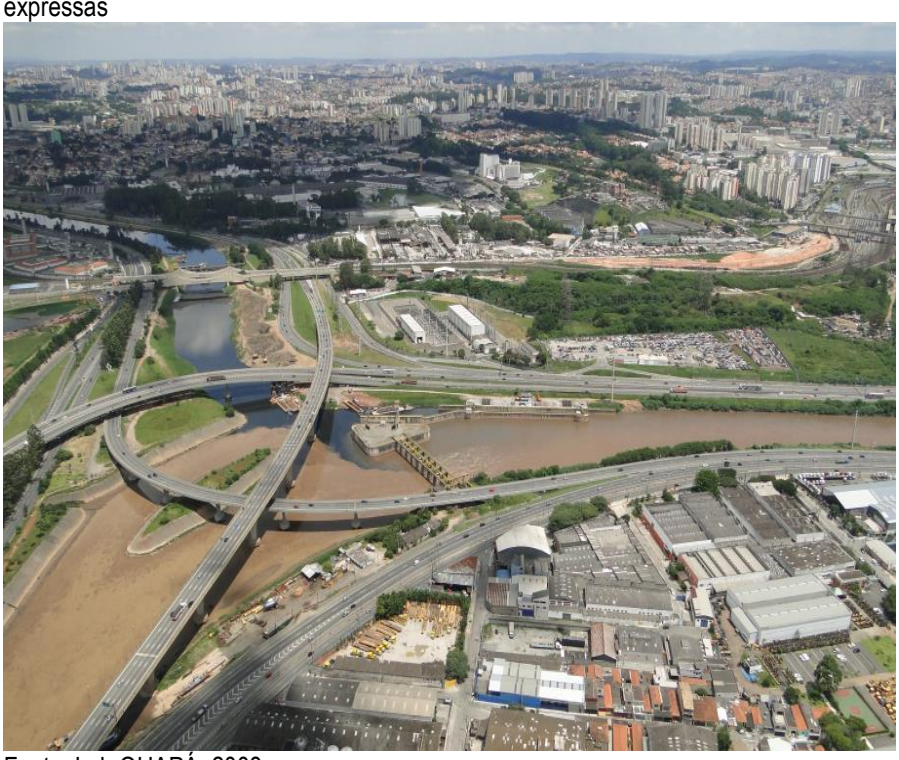

Fonte: Lab QUAPA, 2008

Para realizar a discussão desses temas neste artigo partese de dados sobre espaços livres e forma urbana da RMSP cartografizados e tabulados, elaborados pelo Lab QUAPÁ ${ }^{1}$. No que diz respeito à questão da apropriação pública dos espaços livres, o artigo apoia-se em mais de vinte trabalhos acadêmicos sobre o assunto orientados pelo autor (trabalhos finais de graduação, iniciações científicas, mestrados e doutorados), bem como por dezenas de trabalhos disciplinares de levantamento de apropriações de espaços livres públicos realizados em diversas praças paulistanas, por equipes de alunos da FAUUSP.

\section{Fundamentação e método}

A partir de análise visual de imagens de satélite, bem como do uso do aplicativo Google Street View, o Lab QUAPÁ produziu uma minuciosa cartografia temática em SIG (software ArcGIS) sobre padrões morfológicos e espaços livres, quadra a quadra, para os municípios da RMSP que compõem a mancha urbana conurbada e contínua da metrópole paulistana (vide exemplos nas figuras 2, 6 e 7). A análise dessa cartografia temática é confrontada também com dados censitários cartografizados em SIG, com a tabulação de dados sobre padrões morfológicos e espaços livres de acesso público, conta-se ainda com o apoio de amplo acervo de fotos realizadas a partir de sobrevoos sobre a RMSP nos últimos dez anos.

As categorias morfológicas adotadas não foram criadas de forma apriorística e sim a partir da análise visual de imagens de satélite. Tais categorias são bastante genéricas, visando sua aplicação para qualquer cidade brasileira ${ }^{2}$. Os diversos padrões morfológicos, que não caberiam aqui apresentar, foram agrupados em quatro grandes categorias:

- Horizontais tipo 1 - edificações horizontais de pequeno porte, casario;

- Horizontais tipo 2 - edificações horizontais de médio e grande porte, galpões, shopping centers de até três pavimentos etc.;

- Verticais - quadras predominantemente verticalizadas ou mistas, onde não há predominância significativa nem de edifícios verticais, nem de edificação horizontais;

- Encraves urbanos3, entendidos como grandes áreas urbanas com cerca de $1 \mathrm{~km}$ de extensão ou mais, "encravadas" no tecido urbano e que se constituem em barreira e ruptura da malha urbana tradicional (aeroportos, campus universitários, pátios ferroviários etc.).

No que tange aos espaços livres públicos, foi necessário ir além da nomenclatura oficial dos logradouros. Se o conhecimento das características e do estado de manutenção das ruas e avenidas da metrópole é razoavelmente conhecido pelo público, o porte real do sistema de parques e praças da metrópole paulistana já é algo que foge do senso comum, bem como não se encontram publicações a respeito (na escala metropolitana). Uma das causas se refere à dificuldade de nomenclatura existente, já que parques e praças são nominados como tal pelas municipalidades independente da sua forma, dimensão ou função.

Na RMSP, a análise dos logradouros oficialmente gravados e mapeados como praças envolve diversidade de logradouros como rotatórias e canteiros, espaços em quinas de quarteirões até praças de fato, sendo que muitos destes logradouros não passam, na realidade, de terrenos baldios ou mesmo estão ocupados por prédios públicos ou favelas o que dificulta qualquer forma de análise e avaliação.

O confronto entre a informação oficial dos espaços livres públicos, em relação ao que pode ser visualizado por imagens de satélite (para esta finalidade, foram observadas todas as quadras da capital) e pelo aplicativo Google Street View, levou os pesquisadores do Lab QUAPÁ a definir operacionalmente cada tipo de espaço livre público. Muitos logradouros oficialmente computados pela PMSP como praças, por exemplo, não passam de áreas desocupadas, cheias de mato, outras estão indevidamente ocupadas por edificações, inclusive públicas. 
Para o estabelecimento destas definições, evidentemente, parte-se de discussão conceitual mais complexa sobre a qual já se debruçaram vários pesquisadores do Lab QUAPÁ (MACEDO; ROBBA, 2002, MACEDO; SAKATA, 2003, QUEIROGA, 2012), mas objetivando-se chegar em definições mais simples, precisas e operacionais, que permitem classificar os espaços públicos a partir dos aplicativos acima mencionados.

Adotou-se que praças seriam aquelas que respondessem simultaneamente às condições abaixo:

- Ser oficialmente denominado pelo Poder Público como praça;

- Ocupar ao menos metade de um quarteirão, algo como cerca de 3.000 a $5.000 \mathrm{~m}^{2}$, até aquelas que ocupassem não mais de dois quarteirões;

- Possuir algum tipo de tratamento paisagístico/urbanístico (pisos para pedestres, eventualmente bancos, iluminação pública, arborização, canteiros etc.);

- Ampla acessibilidade física ao usuário comum.

Desta forma, distinguiu-se canteiros, rotatórias e "restos de quadras", aqui entendidos como remanescentes de parcelamento, do que denominou-se, de fato, como praças.

Quanto aos parques, adotou-se os seguintes critérios:

- Ser oficialmente denominado pelo Poder Público como parque;

- Dimensão mínima de meio hectare;

- Possuir algum tipo de infraestrutura capaz de receber visitação pública (pisos ou trilhas para pedestres, eventualmente bancos, iluminação pública, arborização, sanitários etc.);

- Acessibilidade pública.

Definiu-se ainda:

- Praças não implantadas - logradouros públicos oficialmente denominados como praças com área superior a $3.000 \mathrm{~m}^{2}$, porém sem que tenha havido qualquer tratamento urbanístico e/ou paisagístico;

- Praças ocupadas - logradouros públicos oficialmente denominados de praças, porém efetivamente ocupados para outros fins (escolas, postos de saúde, favelas etc.)

- Remanescentes de parcelamento tratados - espaços públicos urbanizados com área inferior a $3.000 \mathrm{~m}^{2}$;

- Remanescentes de parcelamento não tratados espaços públicos não implantados com área inferior a $3.000 \mathrm{~m}^{2}$;
- Ruas de pedestres, aquelas desenhadas preferencialmente para o pedestre, ainda que possam ser utilizadas por veículos de serviço ou outros em situação especial e em baixíssima velocidade;

- Canteiros com pista de pedestres ou ciclovias. Aqui não se incluem as ciclofaixas (faixas pintadas no leito carroçável para uso exclusivo de ciclistas) equivocadamente computadas como ciclovias pela municipalidade paulistana (ao menos entre 2012 e janeiro de 2017).

\section{Resultados e discussão}

A morfologia urbana da metrópole paulistana é predominantemente horizontal, apesar de apresentar imagem de ser muito verticalizada, notadamente na capital, assim como em setores dos demais municípios economicamente mais relevantes da RMSP (Osasco, Guarulhos, São Bernardo do Campo, Barueri, Santo André e São Caetano do Sul), nas suas respectivas áreas centrais e entornos (vide figura 2).

Tomando o caso mais simbólico, a capital de São Paulo, mesmo ela possui a maior parte de sua malha urbana ocupada por um tecido urbano horizontal a despeito de ter a verticalização como destaque de sua imagem urbana. A partir da carta de padrões morfológicos produzida pelo Lab QUAPÁ (figura 2), tem-se, para o caso paulistano, que cerca de $48 \%$ das "quadras urbanas" 4 possuem uma ocupação predominante de construções horizontais de pequeno porte (casario, pequenos estabelecimentos comerciais e de serviço etc.). Permeando a grande mancha horizontal de pequenas edificações, há outra mancha, também horizontal, composta de construções de médio e grande porte, galpões industriais, shopping centers, depósitos etc. Este segundo padrão morfológico horizontal estrutura extensas áreas ao longo das várzeas, de avenidas expressas e arteriais, constituindo $8,5 \%$ do território urbanizado.

Somente $7,2 \%$ das "quadras urbanas" paulistanas são predominantemente ocupadas por edifícios de 4 ou mais pavimentos (aí incluídas também as quadras onde há edifícios de 4 ou mais pavimentos sem que haja clara predominância do padrão vertical ou do padrão horizontal), contrariando a imagem comumente associada à capital paulista. A presença de verticalização se dá também de maneira esparsa por quase toda a cidade, salvo nos bairros exclusivamente residenciais ocupados pela elite, sempre muito protegidos pela legislação de uso e ocupação do solo, bem como ainda são raros os edifícios construídos pelo mercado formal nas periferias mais pobres. Nestas regiões, no entanto, é cada vez mais frequente encontrar-se edificações com mais de três ou quatro pavimentos, aproveitando-se os terrenos 
declivosos, tão comuns nas periferias não só da capital, mas de toda a Região Metropolitana de São Paulo.

Os Encraves se constituem 1,9\% da área total das "quadras" paulistanas. Na RMSP, entre os principais encraves encontram-se os aeroportos (Guarulhos, Congonhas e Campo de Marte), áreas do exército e da aeronáutica em Guarulhos, Osasco e Barueri, o polo petroquímico na Região do $\mathrm{ABC}$ e os depósitos de derivados de petróleo na sub-região Oeste e amplas áreas ferroviárias abandonadas ou subutilizadas, tanto na capital quanto em quase todos os municípios cortados pelas linhas de trem (Figura 2).

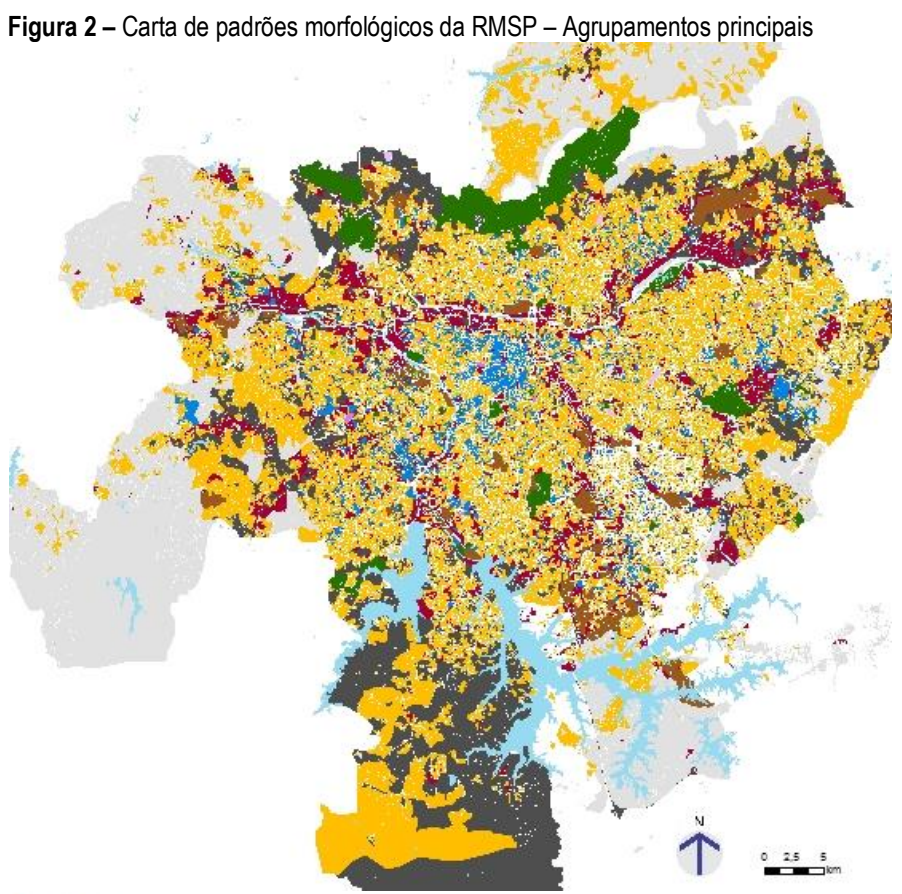

Legenda

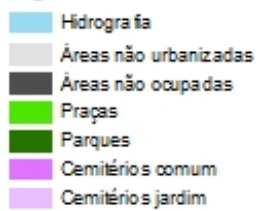

Agrupamentos principais - Volumetria construída

Horizontais tipo 1 Edificacóes honzontais de pequeno porte Horizontais tipo 2 Edifcaçées honzizontais de médio porte Verticais Quadra verticalizada ou mista Encraves urbanos Grandes estruturas urbanas

Os encraves se constituem, portanto, em áreas com alto potencial de reaproveitamento urbano, sejam por iniciativa pública, privada ou consorciada. Tais empreendimentos deveriam considerar não apenas coeficientes de aproveitamento e taxas de ocupação, mas também as demandas metropolitanas no que tange ao sistema de espaços livres de apropriação pública, mas o planejamento metropolitano na RMSP está ainda longe de se ater a estas questões.

No que concerne aos espaços livres da metrópole paulistana, as maiores extensões referem-se às unidades de conservação ambiental - UCs - nas bordas da mancha urbana contínua. São treze unidades de Proteção Integral
- UPIs, totalizando 123 mil ha (SILVA, 2014) . Entre as UPI mais importantes encontram-se os parques estaduais da Serra do Mar e da Cantareira. O primeiro, com 332 mil ha, se constitui na maior UC de Mata Atlântica, conectando florestas ombrófilas densas desde o estado do Rio de Janeiro até o Vale do Ribeira, na porção sul do Estado de São Paulo. Já o Parque da Cantareira, com 7.916,5 ha, encontra-se inteiramente dentro da RMSP, entre os municípios de São Paulo, Caieiras, Mairiporã e Guarulhos.

Na RMSP, encontram-se a sul e sudeste, entre os municípios de São Paulo e Biritiba Mirim, sete reservatórios destinados à captação de água para abastecimento da própria RMSP ou, em alguns casos, uso misto (abastecimento de água e geração de energia). Infelizmente as UPIs existentes constituem modestas porções das bacias e mananciais que abastecem tais represas e, os dois reservatórios mais importantes Billings e Guarapiranga - apresentam forte presença de urbanização periférica com forte lançamento de esgotos em suas águas.

A metrópole não se volta para as represas presentes em seu território. Os reservatórios apresentam grande parte das suas margens de difícil acesso à população para finalidades de lazer público e mesmo como suporte para um potencial sistema de transportes hidroviário metropolitano. Perde-se um dos mais expressivos recursos de paisagem - represas cercadas por Mata Atlântica (Figura 3).

Figura 3 - Vista parcial de São Bernardo do Campo e braço da Represa Billings. Urbanização precária impactando mananciais, reservatórios e remanescentes importantes de Mata Atlântica.

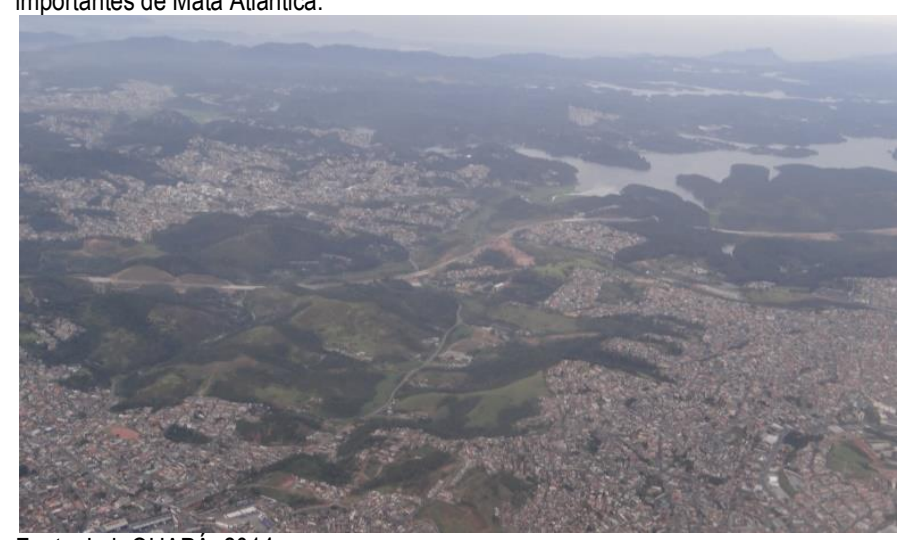

Fonte: Lab QUAPA, 2014

UPIs e represas poderiam ter uma apropriação humana mais significativa e controlada, sobretudo voltada para lazer, atividades esportivas e educacionais. Trata-se de ativos ambientais bastante subaproveitados, contraditoriamente à forte demanda por espaços "naturais" numa metrópole de mais de vinte milhões de habitantes. O resultado é a "fuga" de milhões de cidadãos metropolitanos em automóveis para praias e montanhas 
fora da RMSP a cada feriado prolongado, congestionando rodovias, impactando fortemente o ambiente em busca da "natureza" nas regiões circunvizinhas à RMSP.

Na RMSP o município de São Paulo possui os mais importantes espaços livres de uso púbico, alguns apresentam escala de apropriação metropolitana, atingindo até escalas extra metropolitanas em determinados eventos. Quanto aos espaços do cotidiano, a capital também costuma se colocar como locus pioneiro de diversos lançamentos de formas e de práticas espaciais. Vale, portanto, focar a análise para a capital paulista.

Os espaços livres públicos somam significativos $27,4 \%$ do território do Município de São Paulo, mas quase metade deste percentual é destinado ao sistema viário. Tomando a área de todos os espaços livres de acesso público da capital paulista, aí somados os cemitérios jardins, sejam de propriedade pública ou privada (dado que sua acessibilidade ao público é bastante similar), o município possui 41.695 ha de espaços livres de acesso público, distribuídos percentualmente da seguinte maneira:

- Sistema viário - 47, 9\%;

- Parques - 30,3\%, sendo $27,4 \%$ em unidades de conservação ambiental (parques estaduais ou parques naturais municipais) e somente $2,9 \%$ em parques urbanos;

- Rios e represas $-14,9 \%$;

- Canteiros e rotatórias - 2,4\%;

- Praças - $1,2 \%$;

- Cemitérios jardins - 1,0\%;

- Praças ocupadas (por edificações públicas ou privadas) $-0,6 \%$;

- Praças não implantadas -0,6\%;

- Cemitérios comuns - 0,3\%;

- Espaços livres remanescentes de parcelamento (implantados) - 0,3\%;

- Espaços livres remanescentes de parcelamento (não implantados) - 0,2\%;

- Canteiros com pista para pedestres e bicicletas $-0,2 \%$;

- Ruas de pedestres $-0,02 \%$.

Uma leitura apenas quantitativa dos percentuais acima pode levar a uma avaliação equivocada sobre o sistema de espaços livres (SEL) do município de São Paulo. É necessário aferir a acessibilidade dos espaços livres públicos, a distribuição dos mesmos pelo território, desigualmente qualificados, via de regra em função de sua inserção urbana, mais ou menos periférica. Mesmo assim os dados agregados acima já são bastante reveladores da importância de alguns tipos de espaços livres em detrimento de outros.

Como regra, nas cidades brasileiras, inclusive na metrópole paulistana, onde não são expressivas as áreas de parques de conservação ambiental, o percentual mais expressivo de espaços livres de acesso público é destinado ao sistema viário. São Paulo, embora possua áreas de conservação ambiental relevantes, também possui o maior percentual de espaços livres destinados ao sistema viário, revelando a importância que se dá à circulação veicular. As calçadas na capital, bem como na RMSP, são geralmente estreitas, quase sempre não superiores a $2 \mathrm{~m}$, limitando drasticamente o plantio da arborização viária na maior parte da metrópole. Diante de um relevo muitas vezes acidentado é muito frequente o passeio público apresentar obstáculos, degraus e rampas íngremes, que dificultam e até impedem a circulação longitudinal pelas calçadas.

As apropriações das ruas e avenidas da metrópole paulistana sofreram décadas de declínio, sobretudo nos bairros de renda média e alta, onde condomínios verticais ou horizontais fechados apresentam, desde os anos 1970, áreas de lazer que enfraqueceram a demanda pelo convívio das vias públicas imediatamente lindeiras. No presente há certa retomada pelo uso de ruas, são inúmeras as apropriações que se intensificam: bares com mesas nas calçadas, parklets já disputam em alguns locais específicos da capital o espaço outrora "inquestionável" do estacionamento de automóveis, bicicletas, skates, apropriações de lazer nos fins de semana, festas e manifestações dos mais diversos grupos e demandas políticas (Figura 4).

Nas periferias da metrópole, onde os espaços livres privados são praticamente inexistentes, a vida pública sempre se deu nas ruas. No dia a dia, as ruas são espaço importante de convivência, há também coletivos culturais, atividades das mais diversas religiões, em fim, a rua é o principal espaço da esfera pública, em que pese seu desenho estar voltado para o tráfego de veículos. Hoje, infelizmente, soma-se à vida urbana da periferia o crime organizado e seu controle de espaços públicos pela violência e mesmo pelo lazer, promovendo "pancadões" (misturando shows, bailes funk, venda de drogas e prostituição) que atraem multidões de jovens nas noites de "fim" de semana. 


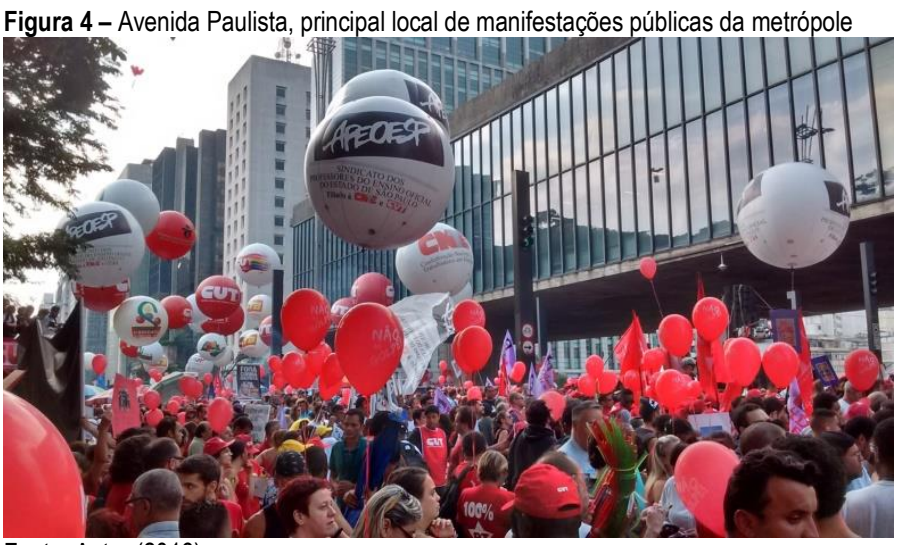

Fonte: Autor (2016)

A metrópole paulistana possui cerca de 200 parques dos mais diversos tamanhos, sendo os maiores UPIs, bastante subaproveitados pelos cidadãos conforme já comentado; a maior parte dos parques da região são de médio ou pequeno porte (entre 1 a 10 ha) e os menores não chegam a meio ha; alguns são bastante equipados, não é o caso da maioria deles. Entre os principais municípios tem-se o seguinte quadro: a capital possui 125 parques, Guarulhos 14, Santo André 11, Osasco 8, São Caetano do Sul 7, São Bernardo possui também apenas 7 parques, mas quase todos bastante bem equipados, entre os quais o Parque da Juventude, com uma das maiores pistas de skate da América Latina e o Parque da Criança, o primeiro parque temático do país (1968), Diadema possui 5 parques, Mogi das Cruzes apenas 3, sendo dois de médio porte (mais de 20ha) e um Parque Natural Municipal (PNM) de 352 ha.

Figura 5 - Parque linear em Guarulhos, bem equipado, situado entre bairros de médio padrão

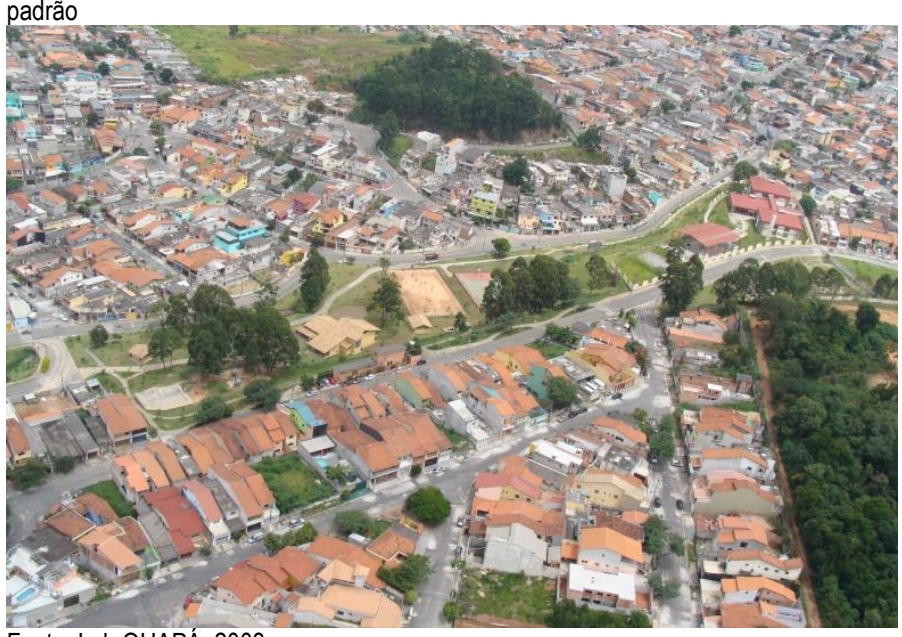

Fonte: Lab QUAPÁ, 2008

A maior parte dos parques da RMSP foi criada a partir dos anos 1990, momento em que as questões ambientais se tornaram mais presentes na esfera pública do país, permitindo consolidar uma legislação e uma agenda ambiental para o meio urbano. Paralelamente, verificouse, sobretudo nas grandes metrópoles, uma crescente demanda por espaços para práticas de atividades físicas, para uma vida mais "saudável", cabendo aos parques urbanos um importante papel no atendimento destas demandas, recebendo cada vez mais público, notadamente aos finais de semana.

Embora o número total de parques na RMSP não seja desprezível, é difícil falar-se em sistema de parques da metrópole, dada a total falta de planejamento metropolitano dos espaços livres público. Alguns municípios possuíram políticas esporádicas em relação a seus sistemas de espaços livres, caso de Santo André e Taboão da serra, por exemplo, mas nada em escala efetivamente metropolitana.

Dos 125 parques paulistanos cerca de cem deles são municipais e os demais estaduais. A maioria situa-se em bairros mais populares e subúrbios, alguns apresentam dimensões diminutas, não chegando a $10.000 \mathrm{~m}^{2}$, área compatível com a dimensão de praças. A despeito disso, podem e devem ser caracterizados como parques, dada sua morfologia que lhes confere grau relativamente maior de interioridade e de "afastamento" do entorno urbano imediato, permitindo certa "pausa" diante do frenesi urbano; exatamente o inverso do que se procura obter numa praça típica, onde as relações com o entorno urbano são o principal fator que lhes potencializa sua dinâmica de vida pública.

A praça é índice do lugar, com ele estabelece fortes relações (QUEIROGA, 2002), já o parque possui relativa autonomia de seu entorno imediato (QUEIROGA, 2012). Não é estranho, portanto, que existam parques menores que algumas praças, mas, para efeito prático, na escala de análise de uma metrópole de proporções tais quais a RMSP, parte-se de algumas métricas como já se definiu no item "Fundamentação e método" deste artigo.

Em São Paulo, os parques públicos de maior dimensão são unidades de conservação (não são parques urbanos, portanto), cumprem importante função ambiental e ecossistêmica, não resta dúvida, mas possuem visitação muito menor que sua capacidade de suporte, poderiam, não apenas prestar serviços ambientais, como também socioculturais, integrando questões educativo-ambientais com maior relevância; tais parques são, de fato, subutilizados em muitos sentidos e funções.

Na capital paulistana, alguns dos maiores parques urbanos, inclusive o maior deles (Parque Anhanguera com 9.500.000 $\mathrm{m}^{2}$ ) são também pouco utilizados no seu todo ou em sua maior parte, seja por falta efetiva de equipamentos básicos de suporte à sua visitação, ou pelo difícil acesso por transportes públicos.

De um total de 7.256 logradouros oficialmente denominados como praças na capital paulistana, identificou-se no Lab QUAPÁ 1.106 praças de fato (segundo os critérios já mencionados no item 
"Fundamentação e método" desse artigo). 3.900 logradouros oficialmente denominados como praças são apenas canteiros e rotatórias, 835 são remanescentes de parcelamento com algum tipo de tratamento, de fato espaços com possibilidades de apropriação pelo público, mas de área muito diminuta para serem plenamente praças públicas e ainda 508 "praças" que nada mais são do que remanescentes de parcelamento sem nenhum tratamento paisagístico. Há 464 "praças" ocupadas ou por prédios públicos, ou por favelas, perdidas para sempre como logradouros de convívio público e lazer. 508 praças não implantadas indicam que não se deveria perder mais tempo para estabelecer uma política de implantação urgente das mesmas ${ }^{5}$, sobretudo diante da dinâmica voraz da urbanização informal pressionada pelos altos custos da terra urbana em São Paulo e pela falta de políticas públicas habitacionais na escala efetiva da demanda.

As áreas de praças são menos expressivas até que a área total dos canteiros e rotatórias. As praças são apenas cerca de metade da área dos canteiros e rotatórias, espaços que, via de regra, são utilizados apenas para orientar o tráfego veicular, em que pese algumas rotatórias terem também importante papel como referência urbana.

As praças paulistanas, em sua grande maioria possuem projetos e manutenção bastante modestos, regra que se verifica também nos demais municípios da RMSP. Encontram-se razoavelmente distribuídas pelas 32 subprefeituras da capital, ainda que internamente a elas, nos seus 96 distritos, observe-se maior heterogeneidade na presença ou ausência de praças. Fato este que se agrava diante da enorme desigualdade socioespacial do município. As praças mais importantes da cidade são já, ao menos, centenárias, reafirmando sua importância simbólica e de uso para a cidade, são objeto de novos projetos com grande recorrência, sobretudo devido o alto grau de visibilidade que possuem como "obra pública". Algumas poucas praças em bairros nobres mais recentes (anos 1970 em diante, tais como a Praça Vinicius de Moraes no Morumbi) são mais bem tratadas que suas congêneres dos bairros de padrão médio, mas não se constituem em regra.

Paralelamente existem ainda os seguintes espaços livres de acesso público:

- 41 cemitérios sendo que 27 deles são cemitériosjardins. No Distrito de Brasilândia e em suas imediações, por exemplo, o maior espaço livre de acesso público é um cemitério. No referido distrito, o Parque Estadual da Cantareira não apresenta núcleo de apoio à visitação pública;

- 202 passeios com ciclovias, isto é canteiros centrais dotados de caminhos para pedestres e/ou bicicletas e tratados com algum tipo de vegetação. No atual século tais caminhos se transformam em espaços de lazer para muitas áreas carentes em parques, são locais de atividade física onde a população, em busca de uma vida mais saudável, ocupa canteiros centrais de avenidas de fundo de vale, cercados pela nociva poluição dos automóveis e demais veículos.

- 11 ruas de pedestres, número bastante diminuto diante do total de cerca de 55 mil vias públicas da cidade. A despeito disso, o sistema de ruas de pedestre da área central da cidade confere característica peculiar ao centro histórico mais importante da metrópole (RUPF; QUEIROGA, 2015), permitindo incontáveis apropriações públicas além do simples, mas fundamental, ir e vir dos transeuntes. O sistema de ruas de pedestres e praças do centro de São Paulo é um dos principais elementos que mantém a vitalidade daquela área, que é centro não apenas da cidade, mas possui escala metropolitana e mesmo macrometropolitana.

No que tange aos espaços livres privados da metrópole paulistana, pátios e quintais de residências e prédios são comumente bastante exíguos e impermeabilizados, sobretudo em áreas ocupadas por camadas de renda média e baixa. Mesmo em bairros residenciais de renda mais elevada, de morfologia predominantemente horizontal, é comum encontrar-se inúmeras quadras com taxas de ocupação superior a 50\%, indicando o papel secundário dos espaços livres privados diante das demandas quase sempre crescentes por espaços edificados. As áreas de menor ocupação acabam se verificando, sobretudo, no entorno das áreas efetivamente urbanizadas da RMSP (Figura 6).

Em decorrência desse fato, a arborização intraquadra na RMSP é em quase todas as áreas de urbanização consolidada muito baixa. Lotes impermeabilizados e baixa arborização urbana vão, evidentemente, impactar severamente o ambiente da metrópole de mais de vinte milhões de habitantes, basta que se recorde os mapas de temperatura aparente da superfície da RMSP, onde as ilhas de calor correspondem às áreas horizontais de alta taxa de ocupação do solo, sensivelmente mais quentes que as áreas mais verticalizadas (os prédios geram mais sombras), ou do que as áreas mais arborizadas.

A exceção maior a este quadro ambientalmente pouco arborizado se verifica nos loteamentos de alto padrão com lotes grandes, superiores a $1.000 \mathrm{~m}^{2}$, como na Chácara Flora, na capital, ou na região da Granja Viana em Cotia e Carapicuíba, ou em alguns loteamentos fechados de Barueri e Santana do Parnaíba (Figura 7). 


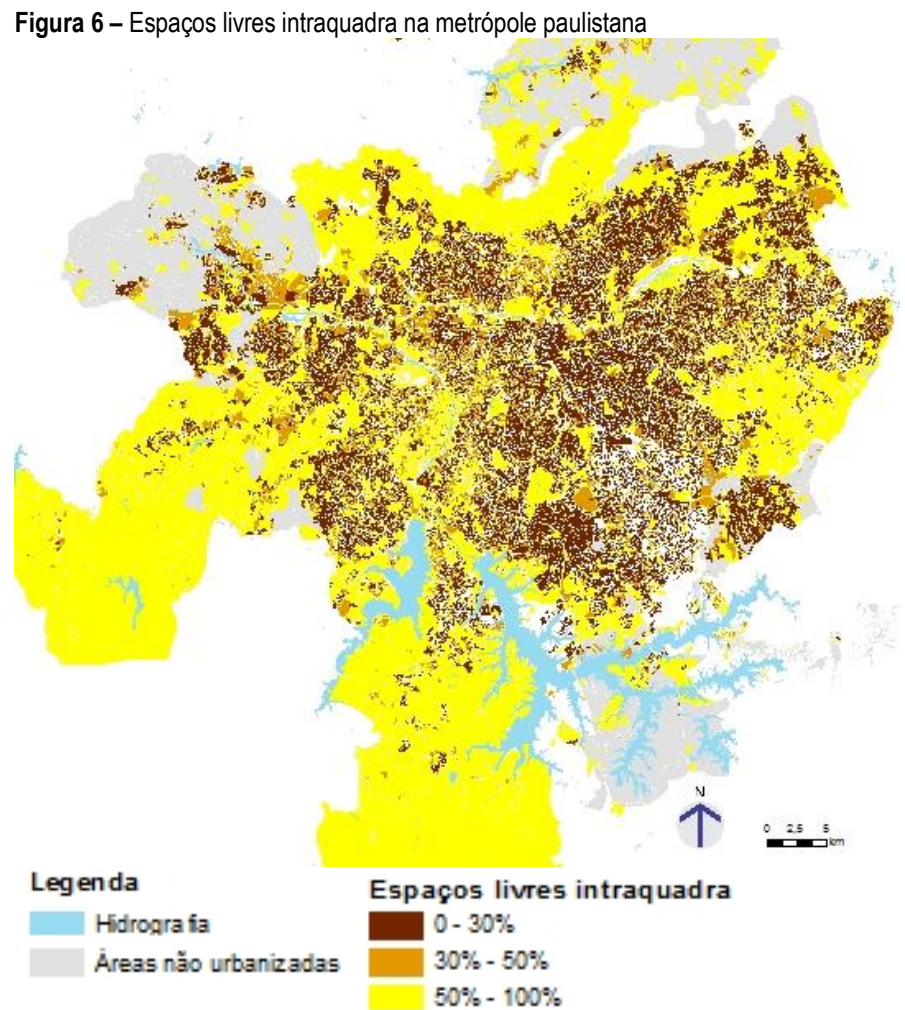

Fonte: Lab QUAPÁ, 2016.

Figura 7 - Arborização intraquadra na metrópole paulistana

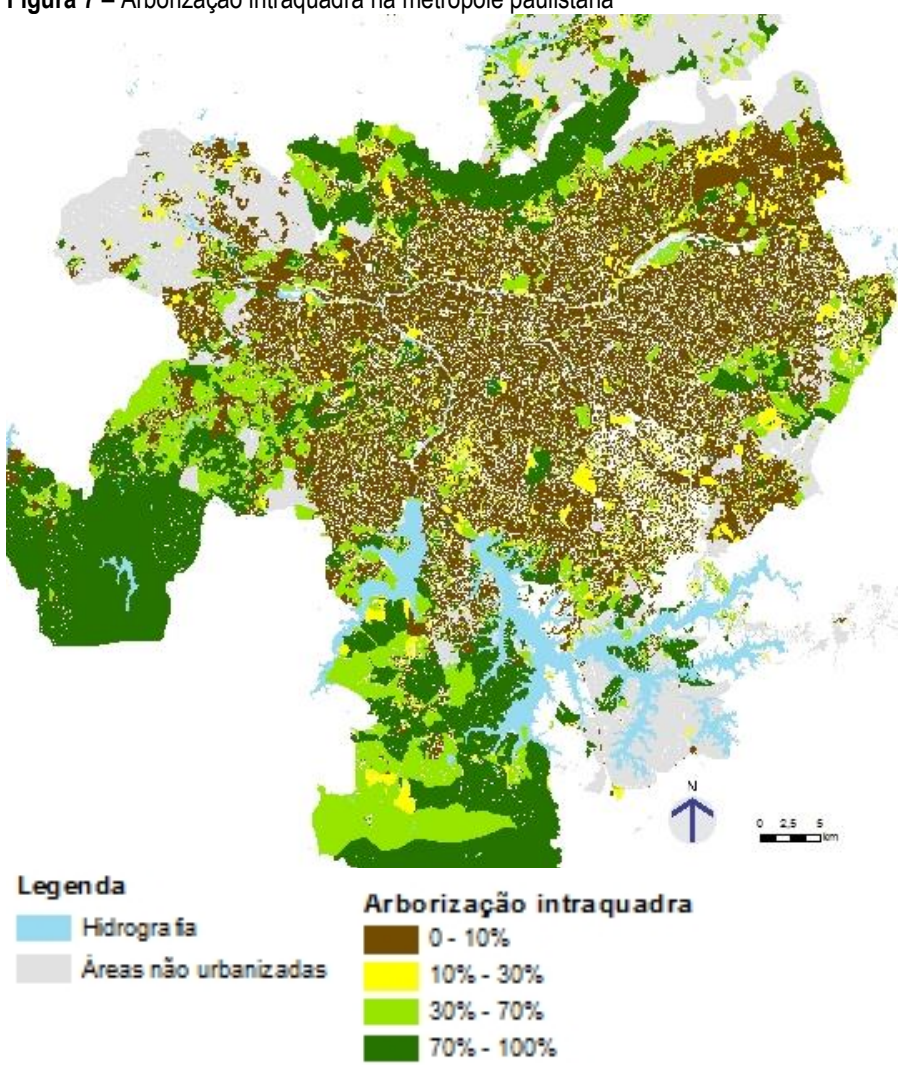

Fonte: Lab QUAPÁ, 2016.

Nas áreas da RMSP de maior preço do solo, nos espaços públicos e privados, são encontradas situações de alta qualidade, como praças e parques tratados com paisagismo de excelência (Figura 8), avenidas e ruas arborizadas, com calçadas largas e confortáveis, áreas comuns e pátios generosos (em especial nas áreas verticalizadas), praças corporativas com desenho requintado, ciclovias bem estruturadas e nos maiores complexos de loteamentos fechados, sobretudo no setor oeste e sudoeste da RMSP, encontram-se algumas áreas de interesse ambiental razoavelmente conectadas (MACEDO, 2012). Desta maneira, embora haja recentes iniciativas de qualificação de espaços livres em áreas periféricas, promovidas por gestões municipais progressistas, o mais comum é encontrar os espaços livres de melhor qualidade nas áreas mais ricas, por vezes inacessíveis à maior parte da população, refletindo e reforçando as desigualdades socioespaciais, marcas contundentes das maiores metrópoles brasileiras.

Figura 8 - Praça Victor Civita, projeto sofisticado implantado cuidadosamente em local de solo contaminado, localizado na Zona Sudoeste de São Paulo, a mais privilegiada da capital.

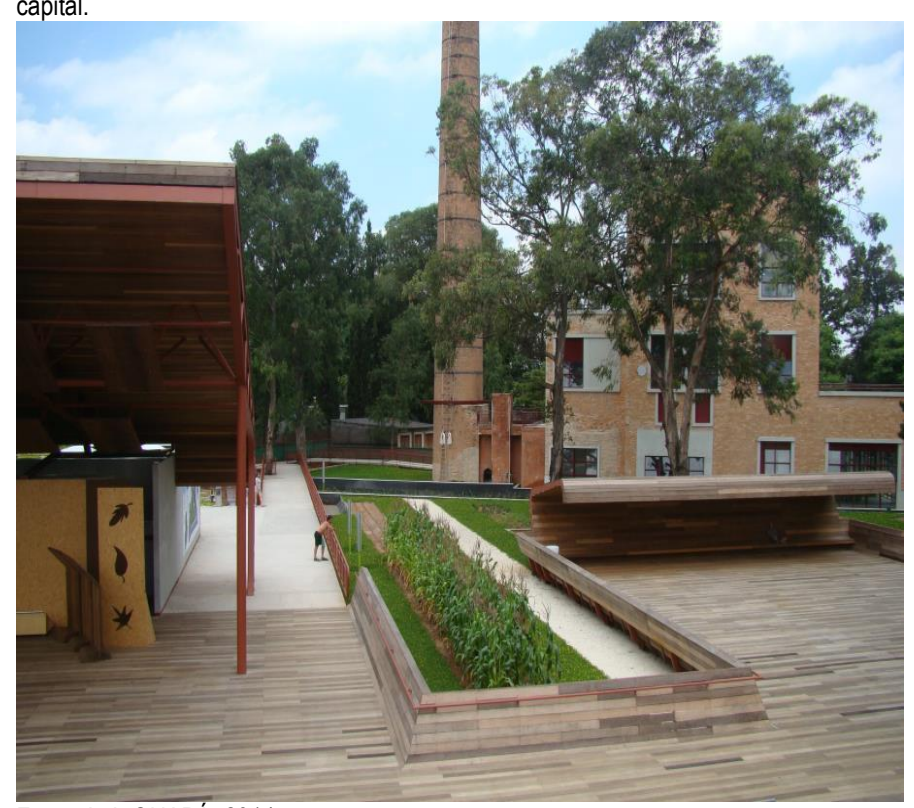

Fonte: Lab QUAPÁ, 2014

\section{Concluindo: perspectivas e desafios}

A urbanização clandestina continua a destruir recursos paisagísticos e ambientais da metrópole (matas e mananciais), ainda que tenha desacelerado fortemente sua escala na última década. Nas últimas duas décadas, a expansão de loteamentos fechados ocupou significativas porções do território da RMSP, sobretudo nos setores oeste e sudoeste, mas também presentes a norte da Serra da Cantareira, a leste de Guarulhos etc. Esse padrão de ocupação, dispersa e fragmentada, acarretou significativos impactos socioambientais, gerando enorme fluxo de veículos, de mão-de-obra e mercadorias, além de impactar negativamente a vida pública em seu entorno imediato. 
Tais impactos poderiam ser evitados caso houvesse efetivo interesse das gestões públicas em coibi-los.

Os condomínios verticais, entre os anos 1990 e 2010 buscaram "qualificar" seus crescentes espaços livres com inúmeros itens de lazer e recreação, dando as costas para as ruas. Somente mais recentemente (2012) se começa a oferecer no mercado produtos imobiliários que procuram valorizar a vida urbana extramuros. A legislação urbanística recém aprovada na capital (Plano Diretor em 2014 e Lei de Parcelamento, Uso e Ocupação do Solo em 2016) apresenta, ainda que de maneira modesta, avanços no intuito de promover maior fruição pública dos espaços urbanos. Espera-se que tais medidas se coloquem enquanto novo paradigma urbanístico para outras cidades da região.

Apesar do incremento neste século no número de parques, a metrópole ainda conta com uma rede muito modesta de espaços públicos destinados ao lazer, fato este devido a anos de falta de investimentos e ausência de políticas públicas continuadas, situação que possibilitou o desaparecimento de um sem número de locais potencialmente adequados para a implantação de novos logradouros públicos de convívio e lazer. Como resultado, a existência de áreas favoráveis ao estabelecimento de novos parques encontra-se praticamente só em zonas mais distantes ou periféricas, ou pela reabilitação de espaços funcionalmente já pouco adequados da metrópole (Figura 9).

Nas áreas mais antigas, consolidadas da capital, especialmente nas zonas leste e norte, assim como em municípios mais periféricos da RMSP de fraca dinâmica econômica, é comum não se encontrar nenhum parque por quilômetros, há, por outro lado, em alguns setores da Zona Oeste da capital e nas bordas urbanas da RMSP, parques não implantados, sejam urbanos, naturais municipais, ou mesmo estaduais, como o Parque Estadual do Itaberaba na região nordeste da RMSP.
Figura 9 - Parque da Juventude, implantado em área anteriormente destinada ao Complexo Presidiário do Carandiru, Zona Norte de São Paulo

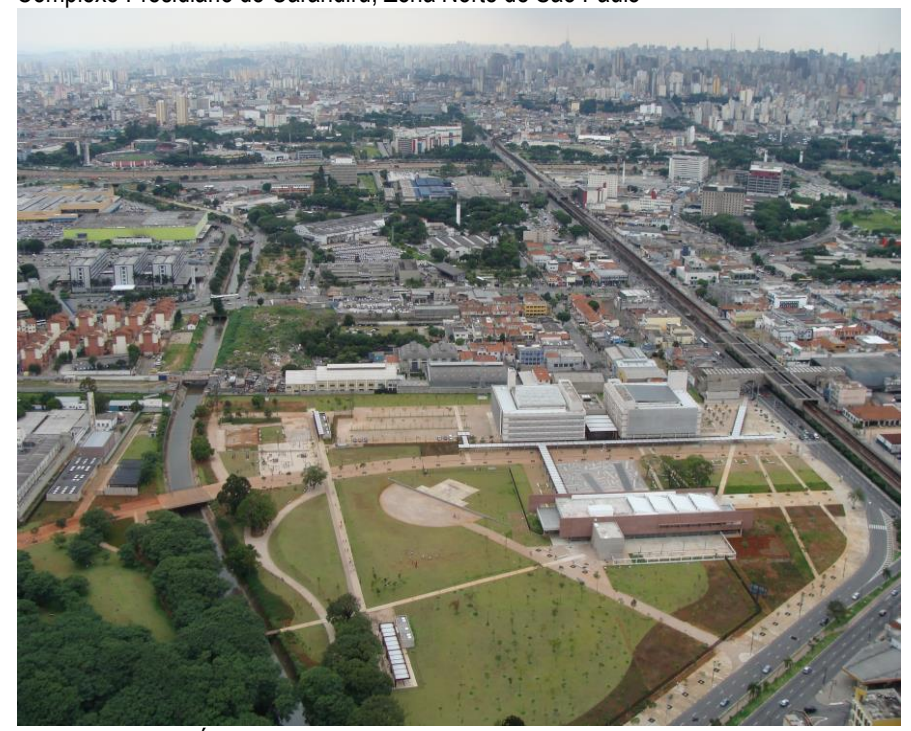

Fonte: Lab QUAPÁ, 2012.

As praças, com a diminuição de novas áreas para loteamentos abertos tem a reserva de novos terrenos para sua implantação decrescente, mas falta ainda muito a ser feito com a grande quantidade de logradouros ainda não instalados.

As principais cidades da metrópole paulistana veem, mais recentemente, discutindo o excessivo espaço destinado aos automóveis e o precário e perigoso espaço para pedestres e ciclistas, porém, sem contar com um sistema de transportes públicos condizente com a escala da metrópole, as soluções são ainda paliativas.

Enfim, o quadro do sistema de espaços livres da RMSP é complexo, dinâmico e desafiador, há muito a ser feito, necessário unir esforços, abrir-se ao diálogo e à cooperação entre as áreas afins, na academia e nas gestões públicas, fomentar a participação popular e superar falsas dicotomias como a opção entre destinar áreas para parques ou para habitação de interesse social, entre preservar a natureza ou realizar apropriação pública adequada dos espaços com forte presença de ecossistemas naturais.

\section{Agradecimentos}

Este artigo não se faria sem o apoio da FAPESP ao Projeto Temático de Pesquisa "Os sistemas de espaços livres na constituição da forma urbana contemporânea no Brasil: produção e apropriação - QUAPÁ-SEL II”. Agradeço também ao CNPq pela Bolsa de Produtividade em Pesquisa, bem como a todos os colegas do Lab QUAPÁ da FAUUSP, cuja interlocução acadêmica e trabalho de sistematização de dados sobre os sistemas de espaços livres das cidades brasileiras já se faz há mais de dez anos.

\section{Notas}

(1) Desde 2006 o Lab QUAPÁ realiza pesquisas sobre sistemas de espaços livres (SELs) e esfera pública em cidades e metrópoles brasileiras, em 2011 iniciou projeto temático sobre SELs e forma urbana. Para a realização da pesquisa em escala nacional o Lab QUAPÁ criou e coordena a Rede Nacional de Pesquisa QUAPÁ-SEL, que agrega atualmente mais 
de vinte núcleos de pesquisa em universidades localizadas em todas as macrorregiões do país. O autor deste artigo integra a coordenação do Lab QUAPÁ e da Rede QUAPÁ-SEL.

(2) Até o presente o Lab QUAPÁ realizou cartografia temática para cerca de 60 cidades do país, incluindo quase todas as capitais, cidades integrantes de metrópoles e algumas cidades médias.

(3) Adotou-se a definição de "encrave" e não de "enclave" para não se confundir a definição aqui enunciada de "encrave" (inspirada no conceito empregado na Ecologia e na Fitogeografia) com o conceito de "enclave fortificado" de Caldeira (2000), comumente empregado na área de Planejamento Urbano, e que não cabe para designar o espaço aqui tratado

(4) Consideram-se "quadras urbanas" toda a área urbanizada do município salvo as áreas ocupadas pelos sistemas hídrico e viário.

(5) Lembre-se que o último programa de implantação mais ampla de praças da cidade de São Paulo foi realizado na Gestão de Marta Suplicy, entre 2001 e 2004, onde se escolheu cerca de 50 áreas, sobretudo periféricas, para a implantação de praças - Programa Centro de Bairros.

\section{Referências}

CALDEIRA, Teresa. Cidade de muros: crime, segregação e cidadania em São Paulo. São Paulo: Editora 34; EDUSP, 2000.

DENATRAN DEPARTAMENTO NACIONAL DE TRÂNSITO. Frota de veículos. Brasília: DENATRAN, 2016.

Disponível em: < http://www.denatran.gov.br/frota2015.htm >. Acesso em: 10 set. 2016.

EMPLASA EMPRESA PAULISTA DE PLANEJAMENTO METROPOLITANO. EMPLASAGEO. Disponível em: <http:// http://www.emplasageo.sp.gov.br >. Acesso em 12 out. 2016.

IBGE INSTITUTO BRASILEIRO DE GEOGRAFIA E ESTATÍSTICA -. Projeção da população do Brasil e das Unidades da Federação. Rio de Janeiro: IBGE, 2016. Disponível em: <http://www.ibge.gov.br/apps/populacao/projecao/>. Acesso em: 13 jul. 2016

MACEDO, Silvio; ROBBA, Fabio. Praças Brasileiras. São Paulo: EDUSP, 2002.

MACEDO, Silvio; SAKATA, Francine. Parques urbanos no Brasil. São Paulo: EDUSP, 2003.

MACEDO, Silvio. Paisagismo Contemporâneo na Virada do Século 1990 - 2010. São Paulo: Edusp, 2012.

RUPF, Lilian Dazzi Braga; QUEIROGA, Eugênio Fernandes. Lugares públicos como potencialidades: uma leitura urbana do centro histórico de São Paulo. Paisagem e Ambiente, São Paulo, n. 35, p. 139-159, oct. 2015. ISSN 2359-5361. p139159. doi:http://dx.doi.org/10.11606/issn.2359-5361.v0i35.

QUEIROGA, Eugenio. A megalópole e a praça: o espaço entre a razão de dominação e a razão comunicativa. 2001.351 p. Tese (Doutorado em Arquitetura e Urbanismo) - Faculdade de Arquitetura e Urbanismo, Universidade de São Paulo, São Paulo, 2002.

QUEIROGA, Eugenio. Dimensões públicas do espaço contemporâneo: resistências e transformações de territórios, paisagens e lugares urbanos brasileiros. 2012. 284 p. Tese (Livre docência em Arquitetura e Urbanismo) - Faculdade de Arquitetura e Urbanismo, Universidade de São Paulo, São Paulo, 2012.

\section{${ }^{1}$ Eugenio Fernandes Queiroga}

Arquiteto e Urbanista. Livre Docente pela Faculdade de Arquitetura e Urbanismo da Universidade de São Paulo. Professor Associado da FAUUSP. Endereço postal: Rua Desembargador Antão de Moraes, 784, Campinas, SP, Brasil, CEP: $13083-310$. 